\title{
DESIGNING NEW GENRE IDENTITIES IN SCIENTIFIC AND TECHNICAL DISCOURSE: COGNITIVE, SOCIAL AND PEDAGOGICAL IMPLICATIONS
}

\author{
Carmen Pérez-Llantada Auría \\ University of Zaragoza
}

\begin{abstract}
The purpose of this paper is to foreground the rhetorical architecture of the new emerging cybergenres in the discourse of English for Science and Technology (E.S.T.) and focus on the cognitive, sociopragmatic and pedagogical implications underlying these new genre identities. In particular, the paper will assess the use of these genre typologies in the E.S.T. classroom to develop the student's awareness of the social dimension of discourse in Internet communications, and also to draw the teacher's attention towards those cognitive aspects of language learning that contemporary cognitive psychology claims. The paper will conclude with some suggestions for a communicative syllabus design in the teaching of this specialised register for academic and professional purposes.
\end{abstract}

\section{INTRODUCTION}

Is not a truly active community evolving in cyberspace? Is not a language such as English a multicultural link among individuals communicating via their isolated computer stations? Can a specific discourse community such as that formed by researchers and professionals in the areas of science and technology join the use of this intercultural language and its universal shared set of values?

In his article "Is There a Text in This Class" Stanley Fish (1980: 171) explained that any interpretive community is made up of a group of members who share interpretive strategies for writing texts, constituting their properties and assigning their intentions. Since Internet's expansion into Europe in the 
1970s (Teeler and Gray 2000: 3), the World Wide Web has represented the starting point of a many-to-many communication. Likewise, the birth of this new 'virtual' linguistic community is the result of the Internet's capacity to function as a vehicle for a universally extended group of language users.

Enrique Alcaraz (2000: 15) remarks that this incredible communications platform has also accentuated the role of the English language in the diffusion of scientific, technical, academic and professional knowledge. Nowadays, researchers, professionals, teachers and students in the scientific and technical fields of knowledge make ample use of written electronic communication in their current tasks: from formal bureaucratic correspondence, personal e-mails or in-company communications to the more informal discussion lists or IRCs (Internet Relay Chats), just to mention some examples.

As a very restricted register exclusively used by an expert membership, English for Science and Technology (heretofore E.S.T.) is grounded on a wellestablished set of grammatical and rhetorical conventions (Barras 1978; Huckin and Olsen 1983; Wilkinson 1991). To borrow Widdowson's (1979: 61) words, "[s]cientific exposition is structured according to certain patterns of rhetorical organisation which, with some tolerance for individual stylistic variation, imposes a conformity on members of the scientific community no matter what language they happen to use".

Deeper analyses like those of functional systemicists (Halliday and Martin 1993; Ventola 1996; Martin and Veel 1998) have paid special attention to the functionality of scientific and technical discourse and have focused on the relations between texts and social contexts rather than on texts as isolated linguistic frameworks. Similar views are shared by well-known genre theorists like John Swales (1990) or Vijay Bathia (1993), whose main contention in their studies is that specialised registers like those of science and technology should better be regarded in the light of the different genre typologies. According to these authors, genres are defined as the different categories of texts that the members of a given discourse community develop in their use of a specialised register. Genres are thus characterized by particular purposes and audiences, certain organising structures and a complex set of rhetorical conventions established by the restricted community which makes use of them. By way of illustration, academic English for the domains of science and technology has developed several "research-process genres" (Swales 1990: 177) such as abstracts, research articles, doctoral dissertations, books and monographs. Some other classical categories of written/spoken genres used for academic and professional communication purposes are also technical reports, instructions, oral presentations and scientific posters.

Remarkably significant was Swales's (1990: 33) apprehension of the concept of 'genre' as a 'slippery term', a 'loose term of art', or a 'fuzzy concept' in an attempt to refer to the indefinite and hyperexpandable (my own 
emphasis) nature of generic typologies considering the multifarious range of language uses. If current textbooks on English for specialised purposes approach the teaching of E.S.T. through a description of these classical genre typologies mentioned above, in their 1994 Academic Writing for Graduate Students. A Course for Nonnative Speakers of English, Swales \& Feak seem to anticipate the need to teach new forms of communicating in English and include in their textbook an appendix devoted to e-mail communications.

Most E.S.T. scientific and technical textbooks provide thorough explanation of the commonest rhetorical functions and techniques for developing specialised texts (see Trimble 1985): definitions, classifications, descriptions, comparisons, contrasts, alternatives, etc. This is the case, for instance, of classical textbooks as those of Zimmerman's (1989) or Hamp-Lyons' \& Heasley's (1987). Many of them also include a descriptive analysis of the most recurrent genres of the register as textual and/or discoursal models for interpreting and producing texts (Weissberg and Buker 1990; Coe et al. 1993; Rollinson 1996). As stated above, research articles, abstracts, technical reports, or instructional literature are widely exploited in these textbooks as examples of real texts subject to slight stylistic variations according to the complexity of their rhetorical purpose and their contexts of use.

A similar trend can be observed in well-known online writing laboratories of scientific and technical English, such as the Online Writing Lab (OWL) at Purdue University in the United States (http://owl.english.purdue.edu/), David McMurrey's Computer Writing and Research Lab at the University of Austin in Texas (http://www.io.com/ hcexres/), the Engineering Writing Center at University of Toronto (http://www.ecf.toronto.edu/ writing/), or Ruth Vilmi's Writing Help (http://www.ruthvilmi.net/hut/LangHelp/Writing/\#technical), among others. These websites contain very useful links and references to academic and technical genres such as abstracts, essays, letters, résumés, reports, proposals, oral presentations, posters or instructions, and represent fruitful pedagogical sources for the E.S.T. teacher in his/her search for models, examples and cases.

Like technical textbooks, these writing labs are also based on a rhetorical approach to language and draw the learner's attention towards questions such as how to understand the context, analyze the audience, articulate the purpose clearly or how to choose a style, level of language, approach to the subject and tone suitable for an effective and appropriate communication. However, these online laboratories hardly ever explore the rhetoric of common electronic communications in current academic and professional situations.

To cover this lack, and considering cybergenres as new emerging genre identities in scientific and technical contexts, it seems appropriate from a pedagogical perspective to place special attention on these kinds of texts, born 
out from real needs of communicating in English. It is precisely through the analysis of these new genres in E.S.T. university courses that we will be able to understand Internet's enormous impact on contemporary society and, sociologically speaking, to see how language always accomodates to social and cultural changes (Halliday 1978; Fasold 1990; Fairclough 1992).

\section{COGNITIVE, SOCIAL AND PEDAGOGICAL IMPLICATIONS OF CYBERGENRES}

With the appearance of what is commonly known as 'cybercommunication,' academic E.S.T. curricula are starting to show a growing interest towards those minor contextual models of academic and professional writing -submission of papers, reprint requests, grant proposals, etc.-, as opposed to the highly constrained textual patterns of research-process genres. If, as said before, Swales wisely defined the term 'genre' as 'a fuzzy concept,' it appears that its scope has widened with these new academic e-genres since almost all researchers and professionals in the areas of science and technology currently make an ample use of the English language via the Internet.

This new sociolinguistic situation brings about several pedagogical implications in the E.S.T. syllabus design. It now seems more appropriate that, together with the conventional textual models of formal academic writing such as the research paper, the abstract or the report -to mention the most rhetorically constrained ones-, some other models of writing as e-mail correspondence, intranet communications, discussion lists and chats should be presented in the classroom as the new genre 'identities' of the scientific and technical register.

The present paper attempts to foreground the linguistic and rhetorical architecture of these new generic categories to draw students' attention towards the socially- and pragmatically-determined conventions used in Internet communications. From a pedagogical perspective, the presentation of pragmatic and rhetorical implications of these electronic genres in the E.S.T. classroom represents new fresh material that easily breaks with the daily routine of the textbook and fosters students' motivation in their learning tasks.

Analyses on the rhetoric of English for cyberspace communication are obviously in their beginnings, and most of them provide useful pedagogical suggestions (Seely 1998; Teeler and Gray 2000). Though the rules of the Internet have not been officially devised, some unofficial rules of interaction seem to be recurrent across computer-mediated messages. Like the more formal, academic research-process genres, the language of the Internet shows its own linguistic conventions, its own reasoning processes and standards of argument, its own purpose and audience, and its own style. However, these particular features of discourse reveal strong differences between electronic 
communication and the classical academic genres used by scientists, engineers and researchers.

Broadly speaking, the new set of conventions sustaining the use of English in the Internet represents a radical shift towards a more conversational and informal style, far from the rhetoric of formal academic genres. Moreover, online communication requires fluency, understood as the ability to handle connected discourse in real time without prior rehearsal -especially in the case of discussion lists or chats. Unlike articles, abstracts or reports, the use of Internet English calls for a greater need to improvise, to maintain continuity in speech and comprehension, to respond immediately to unexpected utterances, and even to make rapid changes of topic and speaker. All this represents a highly complex ability on the part of the learner as it involves grammatical accuracy together with stylistic adequacy according to social expectations.

Starting from the premise that the communicative purpose of a genre constitutes its rationale, and considering that these new generic categories are not prepared or constructed in advance of their communicative instantiation -as articles, abstracts or reports are-, both the structure and linguistic patterns of cybergenres greatly differ from the conventional academic texts. Internet genres are specifically characterised by a need for regular online communication with overseas colleagues, universities and, broadly speaking, any type of interaction within the academic or professional milieux. As a result, the E.S.T. syllabus should emphasise that the aim of an electronic communication is to transmit information in a clear and effective way and in the fastest possible way. This means maximum efficiency and effectiveness with the minimum number of words, thus echoing the well-known Gricean cooperative principle and its four maxims of quantity, quality, manner and relevance. To become effective writers/speakers, students of science and technology should learn to create structurally accurate, functionally effective and communicatively appropriate texts. For curriculum purposes, an activity that has proven to be very useful consists in providing students with some general knowledge of structural and discourse patterns of cybergenres, and then comparing it with their knowledge of conventional academic and professional text types.

As far as content organisation is concerned, cybergenres follow certain structures similar to those ruling formal academic writing, that is to say, texts should be both socially and discursively acceptable by their interpretive community. Writers seek social acceptability on the one hand and discourse texture on the other. The use of Internet English in specialised registers displays a thorough organisation of discourse based on patterns of cohesion and coherence. Embedding these discoursal parameters, two recurrent paradigms operate to organise ideas: the general-specific and the problem- 
solution patterns. The general-specific structure is used to develop texts from introductory and/or general references to particular details. An alternative structure is known as the problem-solving pattern. Devised by Michael Hoey in 1983, it includes general reasoning, effects, causes, possible solutions and the assessment of these solutions.

Manuals of rhetoric for good academic writing point out the use of the IMRD structure -Introduction/Methods/Results/Discussion- as a constraining structural framework for organising conceptual information. This structure is easily applicable to classical genre typologies, mainly, research articles and technical reports. As shown in current academic literature, editorial guidelines of scientific publications of prestige insist on the IMRD paradigm for organising the narrative flow. By contrast, Internet English paves the way to less constricted chronological and logical paradigms in the sequencing of ideas. For example, e-mail messages or intranet communications are often developed according to a more simple -or 'relaxed' so to speak-introductiondevelopment-conclusion pattern. In the introduction, the purpose of the communication is stated: the writer specifies the point or intention of the text. The development section contains details and further information about the point of the message, and in the conclusion the writer usually asks for contact or an answer back.

As stated above, the task of the effective writer in a computer-tocomputer communication is to produce a coherent text and to use cohesive devices in order to create and establish relations of meaning (see Schiffrin 1994). Whereas cohesion (Halliday and Hasan 1976) can be achieved by using discourse links or connective devices, coherence refers to the logical linkage between ideas of a text, sentences or paragraphs (Reid and Lindstrom 1985; White and Arndt 1992). Only by adjusting texts to coherence and cohesion will students be able to create brief, ordered and precise messages, and better develop their linguistic competence.

However, in addition to the rhetorical organisation and development of conceptual knowledge, students of E.S.T. should develop awareness of the pragmatic and social factors underlying the use texts as real instances of language in action. As a matter of fact, cybergenres represent a new way of multicultural communication -as understood in the works of Duranti and Goodwin (1992) or Scollon and Scollon (1994); thanks to electronic genres English has become an intercultural tool for communicating within professional and academic contexts. Consequently, it seems appropriate that students/teachers of E.S.T. should become familiar with this new interdiscourse system of communication by analysing, understanding and assessing those sociopragmatic implications underlying Internet texts.

In particular, the use of genre theory as a methodological procedure in the teaching of E.S.T. may help retrieve students' prior knowledge of social 
and pragmatic conventions. From the perspective of cognitive studies (Skehan 1998; Nuyts and Pederson eds. 1999), the teaching/learning through genres activates mental mappings and constructional schemas. As Schilperoord and Verhagen (in Koenig ed. 1998: 141-142) further explain, "[I]f discourse analysis is a method for investigating cognitive processes in reading and producing discourse, the coherence structure may reveal significant insights in the way people maintain and reveal a cognitive representation of texts".

When producing cybertexts, students are engaged in combining elements of language in an appropriate way to meet the appropriate linguistic demands according to the context of communication. As potential writers, learners should keep in mind that the message must be functionally effective on the one hand, and rhetorically appropriate to situation and interactants on the other hand. Therefore, an effective teaching grounded on communicative activities may prove successful for developing the student's awareness of the constraints of these new genres: the variety of purposes of Internet communication (for example, to transmit intranet information, to make an informal request, or to chat), as well as the multifarious situations and relationships established between addressers and addressees.

As also happens with conventional genres, specific questions about grammar and lexis - a textual coverage, broadly speaking- can be approached by reference to pragmatic goals. In this respect, variations in the degree of formality should be regarded in the classroom as the linguistic reflection of the use of language in different contexts and for different purposes.

Within the Internet code, the relation between writer and reader is based on the premise of respect. Although English for electronic communications tends to be colloquial and informal, a certain degree of politeness always prevails in every written text via Internet. It should be noted, however, that the more formal the purpose of the text, the more strict it is regarding politeness conventions. We should also keep in mind that some of these new written genres are a kind of unplanned discourse, and therefore, the relevant meaning is pragmatic -the result of a contextualised negotiation. As Jacob Mey (1993: 287) explains, "'[c]ontext' is to be taken here not only on the developmental basis for language user activity, but as the main conditioning factor making that activity possible".

From a rhetorical perspective, the teaching/learning of cybergenres should also focus on the use of a very simplified language. The production of electronic texts in English seeks 'maximal relevance' in the message (Sperber and Wilson 1986: 271): clarity, brevity and simplicity -thus allowing an easier processing of information on the part of the addressee. To ensure that the act of communication is relevant to the addressee, students should become familiarised with the use of this simplified lexicogrammar. Simple language facilitates comprehension as much as possible, and leaves no space for an 
ornate style. By way of illustration, there is a recurrent use of ellipsis and abbreviations and, similarly, articles, auxiliaries and personal pronouns are often omitted in the sentences as they are thought to be recoverable by the sender(s).

For questions of relevance, Internet users also prefer to write in the active voice rather than in the passive, the latter being a classical feature in scientific reporting. Formal research literature is overwhelmingly written in an impersonal style with overt references to the author's actions and judgements kept to the minimum, thus suggesting that the finding or theory has been brought into the central grammatical position. On the contrary, Internet English is featured by a more personal and committed style with a wide use of first person pronouns and a direct address to the addressee. In contrast to classical genre typologies, electronic texts make overt references to the writer's opinions and attitudes, as opposed to the strictly referential and analytical writing of articles, abstracts or reports.

For practical reasons -their everyday use of the Internet-, students show special interest in the analysis of those lexical paradigms found in the net. The use of electronic communications has developed a textual code $-\mathrm{a}$ kind of 'jargon' so to speak- for interacting within the community of users, and which is sustained upon solid sociocultural matrices (Tomalin and Stempleski 1993). As sociolinguistic studies point out, cybercommunication makes use of multisemiotic codes - graphic elements- in order to facilitate the interaction between users. For example, the use of capital letters, underscore characters $($ ) or asterisks to place special emphasis on a given part of the message are some of these new textual conventions in electronic texts. It is also interesting for students to analyse in the classroom the use of 'smileys' or 'emoticons' as non-verbal communicative signals which, coming out from keyboard characters, attempt to simulate face-to-face conversations by representing the writer's emotions that we often take for granted in oral communication.

As far as a lexical approach to e-genres is concerned, the development of new terms in cybercommunication could be presented in the classroom as instances of how language evolves according to certain social and cultural contexts of use. New words such as 'snail-mail' (or ordinary mail), 'newbie' (a newcomer in the net), 'net potato' (a couch potato for the net), 'to surf' (to navigate), 'techie' (an expert in the net), 'hacker' ('somebody who breaks software security systems'), among others, are examples of the new Internet terminology that most E.S.T. students often come across in websites, mailing lists, and discussion groups.

It is also well-known among computer-to-computer language users that, in an attempt to eliminate redundancy and be as concise and straightforward as possible, e-writers should use abbreviated terms ('prob' for 'problem', etc.), or words whose spellings resemble their pronunciation ('u' or ' $4 \mathrm{u}$ ' instead of 
'you' or 'for you,' respectively). This tendency towards simplification is also noticeable in the extended use of acronym versions of commonly-used expressions, a usual linguistic practice in informal contexts of language use. The students' active response is easily elicited when asked about those abbreviations scientists and engineers use in non-formal electronic communications: 'ASAP' ('as soon as possible), 'TIA' ('thanks in advance'), 'WRT' ('with respect to'), 'FYI' ('for your information'), 'BTW' ('by the way'), etc. This may prove useful for the teacher to develop the student's awareness towards the functionality of the language; as a matter of fact, abbreviations and acronyms are used, from a pragmatic viewpoint, as a means to communicate information in the fastest and most effective possible way.

\section{CONCLUSIONS}

As this paper has attempted to foreground, to include these new emerging cybergenres in university E.S.T. courses involves several pedagogical advantages for both teachers and learners.

On the part of the teachers both a rhetorical and a genre analysis of Internet communication may help to ground the teaching process upon those cognitive aspects of language learning that psychologists of cognition claim. Robert Ellis (1997) points out that second language acquisition is a complex process and, in the case of E.S.T. this process involves an added difficulty, namely, the degree of specialisation of the scientific and technical register. In this respect, the use of real examples and models of cybertexts activates learners' mental schemata, that is, their prior conceptual and structural knowledge about genre conventions. By grounding the learning of rhetorical and sociopragmatic parameters of Internet English in previous genre and contextual knowledge, both the processing and production of electronic texts become much more effective.

The analysis of real instances of language in use may also develop the student's awareness of the communicative nature of language (Littlewood 1988; Dudley Evans and St. John 1998). A communicative approach based on genre analysis provides a richer rapport for carrying out realistic and motivating language activities. Moreover, the study of language based on real models of communication offers a potential source for communicative tasks in the classroom (see Munby 1978; Nunan 1989), thus eliciting interest in the learning of language through authentic materials suitable for the students' needs.

At the same time, the functionality of discourse put forward by systemic linguists foregrounds the multipurpose nature of any text. As stated earlier, the rhetoric of cybertexts is always subject to the relation between addressor and addressee as well as to the setting and the circumstances in which the act of 
communication occurs; what is important is the effectiveness involving the purpose of the text and the pragmatic appropriateness of the text style. A discourse approach thus helps students become aware of the way we construct social relations among social subjects by means of a complex mapping of sociocultural practices.

From the perspective of critical discourse analyses (Fairclough 1995; Cederblom and Paulsen 2001), a thorough coverage of those genres used in specialised registers may allow students to evaluate how any language influences and is influenced by social and cultural factors. As Fairclough (1995: 2) concludes, "[t]he heterogeneities of texts are a sensitive indicator of sociocultural contradictions, and a sensitive barometer of their evolution". From this perspective, the teaching/learning process may be useful to bridge the gap between textual and contextual approaches in E.S.T. discourse practices. In particular, the awareness of the social dimension of Internet language may reinforce what A. Johns (1997: ix) calls "socioliterate competence", understood as

[...] being familiar with the strategies needed for understanding and organizing texts, knowing the social contexts in which texts are produced and read, being acquainted with the community and culture that produce and value certain texts and types of texts, and knowing how previous experiences of literacy shape perceptions and expectations as to the nature of written discourse.

As a sociorhetorical construct, the use of English for the production of Internet texts offers particularly interesting insights on the difficult but important issue of E.S.T. rhetorical variations across cultures and generations. Likewise, the semiotic dimension of these new contextual models of specialised writing leads us to conclude that any given message belongs to a general system of cultural and societal values. The sociopragmatic approach draws teachers and learners towards a deeper analysis of the concept of 'genre' in specific registers. This approach entails the need to adapt new materials and methodologies to cover real needs of students when using English to communicate via the Internet.

The combination of rhetorical, discourse and genre perspectives in the E.S.T. classroom clearly displays a consistent pragmatic influence underlying language in use. Only by knowing the different and multifarious genre typologies conforming a specific type of discourse will learners better understand the communicative nature of a language. As exemplified throughout this paper, even in the cyberspace dimension language always turns out to be not only a linguistic enterprise but rather a sociopragmatic undertaking. 
To keep up with the new signs of the times, rhetorical analyses of cybergenres thus prove to be pedagogically successful to emphasise the new dimension of English as a worldwide communicative tool in the fields of $s$ cience and technology. This is, obviously, an area of research full of potential pedagogical implications and in need of further cognitive, discoursal and sociological inquiry.

\section{REFERENCES}

Alcaraz, E. 2000. El inglés profesional y académico. Madrid: Alianza Editorial.

Barras, R. 1978. Scientists Must Write. A Guide to Better Writing for Scientists, Engineers and Students. London \& New York: Chapman \& Hall.

Bhatia, V. J. 1993. Analysing Genre: Language Use in Professional Settings. Harlom: Longman.

Cederblom, J., and D. W. Paulsen. 2001. Critical Reasoning. Understanding and Criticizing Arguments and Theories. Belmont, CA.: Wadsworth/Thomson Learning.

Coe, N., R. Rycroft and P. Ernest. 1983. Writing Skills. A Problem-solving Approach. Cambridge: Cambridge University Press.

Dudley-Evans, T., and M. J. St. John. 1998. Developments in English for Specific Purposes. A Multidisciplinary Approach. Cambridge: Cambridge University Press.

Duranti, A., and C. Goodwin, eds. 1992. Rethinking Context: Language as an Interactive Phenomenon. Cambridge: Cambridge University Press.

Ellis, R. 1997. Second Language Acquisition. Oxford: Oxford University Press.

Fairclough, N. 1992. Discourse and Social Change. Cambridge: Polity Press.

Fairclough, N. 1995. Critical Discourse Analysis. Harlow: Longman.

Fasold, R. 1990. The Sociolinguistics of Language. Oxford: Blackwell.

Fish, S. 1980. "Interpreting the Variorum". Is There a Text in this Class? Cambridge, Mass.: Harvard University Press, 147-173.

Halliday, M. A. K. 1978. Language as a Social Semiotic. The Social Interpretation of Language and Meaning. London: Edward Arnold.

Halliday, M. A. K., and R. Hasan. 1976. Cohesion in English. London: Longman.

Halliday, M. A. K., and J.R. Martin. 1993. Writing Science. Literacy and Discursive Power. London: The Palmer Press. 
Hamp-Lyons, L., and B. Heasley. 1987. Study Writing. A Course in Written English for Academic and Professional Purposes. Cambridge: Cambridge University Press.

Hoey, M. 1983. On the Surface of Discourse. London: Allen \& Unwin.

Huckin, T. N., and L. A. Olsen. 1983. English for Science and Technology: A Handbook for Non-native Speakers. New York: McGraw-Hill.

Johns, A. 1997. Text, Role and Context. Developing Academic Literacies. Cambridge: Cambridge University Press.

Littlewood, W. 1988. Communicative Language Teaching. An Introduction. Cambridge: Cambridge University Press.

Martin, J. R., and R. Veel, eds. 1998. Reading Science. Critical and Functional Perspectives on Discourses of Science. London: Routledge.

Mey, J. L. 1993. Pragmatics. An Introduction. Oxford \& Cambridge: Blackwell.

Munby, J. 1978. Communicative Syllabus Design. Cambridge: Cambridge University Press.

Nunan, D. 1989. Designing Tasks for the Communicative Classroom. Cambridge: Cambridge University Press.

Nuyts, J., and E. Pederson, eds. 1999. Language and Conceptualization. Cambridge: Cambridge University Press.

Reid, J. M., and M. Lindstrom. 1985. The Process of Paragraph Writing. New Jersey: Prentice Hall.

Rollinson, P. 1996. An Introduction to Academic Writing. Madrid: Ediciones de la Universidad Autónoma de Madrid.

Schiffrin, D. 1994. Approaches to Discourse. Oxford: Blackwell.

Schilperoord, J., and A. Verhagen. 1998. "Conceptual Dependency and the Clausal Structure of Discourse". Discourse and Cognition. Bridging the Gap. Ed. J.P. Koenig. Stanford, CA: CSLI Publications, 141-163.

Scollon, R., and S. W. Scollon. 1994. Intercultural Communication. Oxford: Blackwell.

Seely, J. 1998. The Oxford Guide to Writing and Speaking. Oxford: Oxford University Press.

Skehan, P. 1998. A Cognitive Approach to Language Learning. Oxford: Oxford University Press.

Sperber, D., and D. Wilson. 1986. Relevance. Communication \& Cognition. London: Blackwell.

Swales, J. 1990. Genre Analysis. English in Academic and Research Settings. Cambridge: Cambridge University Press.

Swales, J., and C. B. Feak. 1994. Academic Writing for Graduate Students. A Course for Nonnative Speakers of English. Michigan: The University of Michigan Press. 
Teeler, D., and P. Gray. 2000. How to Use the Internet in ELT. Harlow, Essex: Pearson Education Ltd.

Tomalin, B., and S. Stempleski. 1993. Cultural Awareness. Oxford: Oxford University Press.

Trimble, L. T. 1985. English for Science and Technology. A Discourse Approach. Cambridge: Cambridge University Press.

Ventola, E. 1996. "Packing and Unpacking of Information in Academic Texts". Academic Writing. Intercultural and Textual Issues. Eds. E. Ventola and A. Mauranen. Amsterdam: John Benjamins Publishing Company, 153-195.

Weisberg, R., and S. Bucker. 1990. Writing Up Research. Experimental Research Report Writing for Students of English. New Jersey: Prentice Hall.

White, R., and V. Arndt. 1992. Process Writing. London \& New York: Longman.

Widdowson, H. G. 1979. Explorations in Applied Linguistics. Oxford: Oxford University Press.

Wilkinson, A. M. 1991. The Scientist's Book for Writing Papers and Dissertations. New Jersey: Prentice Hall.

Zimmerman, F. 1989. English for Science. New Jersey: Prentice Hall.

\section{ELECTRONIC REFERENCES}

http://owl.english.purdue.edu/ (15/03/03)

http://www.io.com/ hcexres/ (15/03/03)

http://www.ecf.toronto.edu/ writing/ (15/03/03)

http://www.ruthvilmi.net/hut/LangHelp/Writing/\#technical (15/03/03) 